\title{
Evaluation of Arginine-Nitric Oxide Pathway in Patients with Hyperthyroidism
}

\author{
Huseyin Vural ${ }^{1 \star}$, Mehmet Numan Tamer ${ }^{2}$, Ralf Weiskirchen ${ }^{1}$
}

\begin{abstract}
${ }^{1}$ Institute of Molecular Pathobiochemistry, Experimental Gene Therapy and Clinical Chemistry, RWTH University Hospital Aachen, Aachen, GERMANY ${ }^{2}$ Department of Endocrinology, Suleyman Demirel University, Faculty of Medicine, Isparta, TURKEY

*Corresponding Author: drvural@gmail.com
\end{abstract}

Citation: Vural H, Tamer MN, Weiskirchen R. Evaluation of Arginine-Nitric Oxide Pathway in Patients with Hyperthyroidism. Electron J Gen Med. 2021;18(2):em278. https://doi.org/10.29333/ejgm/9696

ARTICLE INFO

Received: 27 Sep. 2020

Accepted: 1 Dec. 2020

\begin{abstract}
There is a reciprocal regulation of arginase and nitric oxide synthase in L-arginine metabolizing pathways. Nitric oxide has been claimed as an important role player in hyperthyroidism in recent years. The fact that arginase is an important part of regulation of arginine has not been investigated yet in terms of nitric oxide synthase activity in hyperthyroidism. This study aims to investigate arginase, manganese (a cofactor of arginase) and total nitrite levels (a metabolite of nitric oxide) and their relationship to the arginine- nitric oxide pathway in patients with hyperthyroidism. Arginase activities, manganese, and total nitrite levels were measured in plasma samples from 50 patients with hyperthyroidism and 50 healthy age- and gender-matched control subjects. Plasma arginase activities were found to be significantly lower and total nitrite level higher in patients with hyperthyroidism than those of controls. Manganese levels were not significantly different in hyperthyroidism group compared to those of controls. Our results demonstrate that the arginine-nitric oxide pathway is implicated in the cardiovascular manifestations of hyperthyroidism which may be of clinical relevance.
\end{abstract}

Keywords: hyperthyroidism, arginase, manganese, nitric oxide

\section{INTRODUCTION}

Thyroid diseases are common endocrine disorders in humans and accompanied by important changes in hemodynamic and cardiac function [1-3]. Thyroid hormones have multiple effects on the cardiovascular system, exerted through both direct and indirect mechanisms of action. Patients with thyroid disease often have clinical manifestations suggesting changes in cardiovascular hemodynamics [3,4] Hyperthyroidism manifests a hyperdynamic circulation with increased cardiac output, increased heart rate and decreased peripheral resistance [5].

The mechanisms by which thyroid hormones affect vascular physiology are not fully understood. However, few data are available regarding the effects of thyroid hormones on endothelial function. Endothelium is metabolically active and plays a key role in vascular hemostasis by secreting numerous autocrine and paracrine substances. One of the major endothelium-derived vasoactive mediators is nitric oxide (NO). It is well known that NO is an important factor regulating vascular tone which accounts for the powerful vasodilator effects of endothelium-derived relaxing factor [6,7]. L-arginine is the main source of NO generation via NO synthase (NOS). Larginine is also a substrate of the enzyme arginase. Arginase and NOS compete with each other for L-arginine because they use the same substrate [8]. There is a reciprocal regulation between arginase and NOS in the pathways of L-arginine metabolism. [8-10]. Arginase requires manganese ( $\mathrm{Mn})$ as a cofactor for its catalytic activity and stability [11]. There is a direct correlation between arginase activity and $\mathrm{Mn}$ level in the body [12]. Arginase activity related studies are available in various endocrine disorders such as diabetes and metabolic syndrome [13,14].

Our main objective in this study was to investigate the arginine-NO pathway by measuring plasma total nitrite, arginase and $\mathrm{Mn}$ in hyperthyroidism. Although there are some studies dealing with NO levels, NOS activity and plasma concentration of asymmetric dimethylarginine, an endogenous inhibitor of NOS in the hyperthyroidism [1,15-19], to our knowledge, this is the first report which has investigated arginase activity and Mn levels together with NO levels in hyperthyroidism.

\section{MATERIALS AND METHODS}

All subjects were informed about the study and their prior written informed consent was obtained. If cooperation with patients is impossible, consent was obtained from the relatives of the patients and the hospital authority. The investigation conformed to the principles outlined in the Declaration of Helsinki.

\section{Patients}

Fifty patients with hyperthyroidism were included in this study. Causes of hyperthyroidism were Graves' disease $(n=35)$, toxic adenoma $(n=9)$ and toxic multinodular goiter $(n=6)$. The 
control group consisted of fifty age- and sex-matched healthy subjects. The patients and control subjects were also matched according to smoking. Patients with regular drug ingestion, chronic systemic diseases such as diabetes mellitus, hypertension, etc., patients with liver and kidney disease were excluded from the study. Clinical diagnosis was supported by plasma fT3, fT4, TSH and thyroid scan determinations.

\section{Sample Collection and Preparation}

Venous blood samples were collected after the patients had fasted overnight. Samples drawn from an antecubital vein were immediately transferred into heparin-containing tubes and centrifuged at $2500 \mathrm{rpm}$ for 10 minutes. Plasma samples were kept at $-70^{\circ} \mathrm{C}$ for subsequent assays and all the measurements were performed at the same time.

\section{Measurement of Plasma Levels of Total Nitrite}

The NO content of the plasma was measured in ELISA (ELx808 Absorbance Microplate Reader, BioTec Instrument Inc. Vermont, USA) by using commercial kits (Nitrate/nitrite colorimetric assay kit, Cayman Chemical Co. Catalog No: 780001, Michigan, USA). This kit employs a nitrate reductase for enzymatic reduction of nitrate to nitrite, prior to measurement of the nitrite levels using the Griess reagent, as described previously [20]. The nitrite level measured using this system represents the total levels of both NO metabolites (nitrate and nitrite). Results were expressed as micromoles of NO per liter ( $\mu \mathrm{mol} / \mathrm{L})$.

\section{Measurement of Plasma Arginase Levels}

Plasma arginase activity was measured according to the method of Geyer and Dabich [21] with some modification for plasma. The urea level was measured spectrophotometrically through the method of thiosemicarbazide-diacetyl-monoxime urea in the supernatants. One-unit plasma arginase was defined as the enzyme activity that produces $1 \mu \mathrm{mol}$ of urea per minute. In addition, protein was determined using the Biuret method. As enzyme activity was very low in plasma samples, the specific activity was expressed as units per gram protein by the measurement of the activity in $1 \mathrm{ml}$ plasma per hour divided by the amount of protein in $1 \mathrm{ml}$ of plasma.

\section{Measurement of Plasma Mn Levels}

Determination of plasma Mn was performed by Perkin Elmer AAnalyst 800 Atomic Absorption Spectrometer (Shelton, CT, USA), according to the method of Brodie and Routh [22]. Plasma was diluted $(1: 2)$ with aqueous $0.1 \%$ Triton X-100 solution, and thoroughly mixed by a vortex mixer. The diluted plasma was used directly for the analysis. The total volume inserted in the tube was $20 \mu \mathrm{L}$. All determinations were run in duplicate, and individual values were averaged. Absorption readings were measured at peak height. The variation coefficient for replicate measurement was less than $3 \%$.

\section{Statistical Analyzes}

SPSS for Windows computing program version 16.0 (IBM Inc, Chicago, IL) was used for the analyses. Data were analyzed using parametric statistical methods. The Student's t tests were used for pair-wise comparisons. Bivariate comparisons were examined using the Pearson rank correlation coefficients ( $r$ ) and values corrected for ties. Two-tailed significance values were used. $p<0.05$ was considered significant in all tests.
Table 1. The characteristics and plasma levels of arginase, $\mathrm{Mn}$ and total nitrite in patients with hyperthyrodism and controls

\begin{tabular}{cccc}
\hline Parameter & $\begin{array}{c}\text { Control } \\
(\mathbf{n}=\mathbf{5 0})\end{array}$ & $\begin{array}{c}\text { Hyperthyroidism } \\
(\mathbf{n}=\mathbf{5 0 )}\end{array}$ & \\
\hline Age $($ mean \pm SD), years & $39.5 \pm 6.4$ & $42.7 \pm 8.9$ & $\mathrm{p}>0.05$ \\
\hline Gender & $20 \mathrm{M} / 30 \mathrm{~F}$ & $18 \mathrm{M} / 32 \mathrm{~F}$ & $\mathrm{p}>0.05$ \\
\hline Smoking & $25(\% 50)$ & $23(\% 46)$ & $\mathrm{p}>0.05$ \\
\hline Total nitrite $(\mu \mathrm{mol} / \mathrm{L})$ & $7.92 \pm 2.69$ & $9.79 \pm 4.17$ & $\mathrm{p}<0.01$ \\
\hline Arginase $(\mathrm{U} / \mathrm{g} \mathrm{protein})$ & $9.77 \pm 4.62$ & $7.76 \pm 3.71$ & $\mathrm{p}<0.05$ \\
\hline Manganese $(\mu \mathrm{g} / \mathrm{L})$ & $2.64 \pm 1.76$ & $2.16 \pm 1.71$ & $\mathrm{p}>0.05$ \\
\hline
\end{tabular}

\section{RESULTS}

As to the social and demographic data (e.g. age, or sex), patients and the controls showed homogeneity, and there were no significant differences between the groups $(p>0.05)$.

As shown in Table 1, plasma NO level of patients with hyperthyroidism was significantly higher $(p<0.05)$, whereas plasma arginase activities were significantly lower $(p<0.05)$ than that of control subjects. We did not observe any significant correlations between these parameters in patients with hyperthyroidism and controls.

\section{DISCUSSION}

There is no study which has investigated arginase activity and $\mathrm{Mn}$ levels together with NO levels in hyperthyroidism. In this study plasma arginase activities were found to be significantly lower and total nitrite level higher in patients with hyperthyroidism than those of controls.

A limited number of studies investigating the NO levels in patients with hyperthyroidism are available. Also, there are studies about NOS and ADMA, which an endogenous inhibitor of NOS. However, the findings on NO levels in patients with hypothyroidism are controversial in the literature. Some researchers $[15,23]$ have found higher plasma levels of NO in consistent with our results, and others $[16,17]$ have determined lower levels of NO in contradiction with our results. Quesada et al. [1] have found high NOS activity in all tissues of hyperthyroid rats. The NOS catalyzes nitric oxide synthesis from L-arginine. The high activity of this enzyme is compatible with high levels of NO. On the contrary, Hermenegildo et al. [16] have found high levels of ADMA, an endogenous inhibitor of NOS, in hyperthyroid patients. A great number of studies in the literature suggest that there is a competition between arginase and NOS and that they control each other's levels. In a study, the arginase was found to be the major pathway of L-arginine metabolism in woman with metabolic syndrome [13]. Also according to our previous results, in patients with Alzheimer disease had high NO levels and low arginase activity [24]. Therefore, we measured arginase and NO levels together based on this reciprocal relationship. Our results indicate that NOS is the major pathway that metabolizes L-arginine in patients with hyperthyroidism.

To our knowledge there is no report about arginase activity in patients with hyperthyroidism. This study is the first report on the arginase activity in these patient groups. In our study, plasma arginase activities were significantly lower in patients with hyperthyroidism than those of controls. The decreased arginase activity can be explained by low $\mathrm{Mn}$ concentrations, because arginase requires $\mathrm{Mn}$ for its catalytic activity and 
stability and Mn deficiency reduces the arginase activity. But in our study, there was no statistically significant difference between the $\mathrm{Mn}$ levels. The mechanism responsible for the reduction of arginase activity in hyperthyroid patients is not known. One possible reason of low arginase activities may result from high NO levels. However, it is not clear whether low arginase activity due to a reciprocal arrangement leads to a high NO level or whether a high NO level leads to low arginase activity.

Mn levels in patients with hyperthyroidism also tended to be lower, but significance was not reached. If the number of cases is increased, a significant difference can be found between Mn levels of both groups. In our study, the number of cases is a limiting factor that may affect $\mathrm{Mn}$ results. In the literature, we found only two studies of the erythrocyte levels of $\mathrm{Mn}$ in patients with hyperthyroidism. In 1984, Aihara et al. [25] showed that there was no statistically significant difference between erythrocyte Mn levels of both groups which supports the findings of our study. In the other study, contrary to our results, serum $\mathrm{Mn}$ levels were found to be significantly higher in hyperthyroidism [26]. Importance of iodine and selenium in thyroid metabolism is well known, but the roles of other essential trace elements including $\mathrm{Mn}$ on thyroid hormone homeostasis remain unclear. Mn levels were higher in other thyroid diseases such as non-toxic diffuse goiter and euthyroid multinodular goiter $[27,28]$.

In conclusion, lower arginase and higher NO levels found in patients with hyperthyroidism may suggest a pathway that favors NO synthesis. This study has a potential to open new perspectives concerning the relationships between arginase activity/NO level and hyperthyroidism. Moreover, the finding of this study demonstrates that arginine-NO pathway may be implicated in the pathogenesis of hyperthyroidism which may be a high clinical relevance. On the other hand, further clinical studies that would have more patients and controls are needed to reach more comprehensive results and to clarify the relationship between NO metabolism and hyperthyroidism.

Author contributions: All authors have sufficiently contributed to the study, and agreed with the results and conclusions.

Funding: No funding source is reported for this study.

Declaration of interest: No conflict of interest is declared by authors.

\section{REFERENCES}

1. Quesada A, Sainz J, Wangensteen R, Rodriguez-Gomez I, Vargas F, Osuna A. Nitric oxide synthase activity in hyperthyroid and hypothyroid rats. Eur J Endocrinol 2002;147(1):117-22. https://doi.org/10.1530/eje.0.1470117 PMid:12088928

2. Larsen PR, Davis TF, Hay ID. The thyroid gland. In Williams Textbook of Endocrinology, edn 6, pp 389-515. Eds JD Wilson, DW Foster, HK Kronenberg \& PR Larsen. London: WB Saunders \& Co., 1998.

3. Klein I. Thyroid hormone and the cardiovascular system. Am J Med 1990;88(6):631-7. https://doi.org/10.1016/00029343(90)90531-H

4. Gomberg-Maitland M, Frishman WH. Thyroid hormone and cardiovascular disease. Am Heart J 1998;135(2):187-96. https://doi.org/10.1016/S0002-8703(98)70081-X
5. Klein I \& Ojamaa K. Thyroid hormone and blood pressure regulation. In Hypertension: Pathophysiology, Diagnosis and Management, edn 2, pp 2247-2262. Eds JH Laragh \& BN Brenner. New York: Raven Press Ltd, 1995.

6. Gardiner SM, Compton AM, Bennett T, Palmer RMJ, Moncada S. Control of regional blood flow by endotheliumderived nitric oxide. Hypertension 1990;15(5):486-92. https://doi.org/10.1161/01.HYP.15.5.486 PMid:2332239

7. Romero JC, Lahera V, Salom MG, Biondi ML. Role of the endothelium-dependent relaxing factor nitric oxide on renal function. Journal of the American Society of Nephrology 1992;2(9):1371-87.

8. Durante W, Johnson FK, Johnson RA. Arginase: a critical regulator of nitric oxide synthesis and vascular function. Clin Exp Pharmacol Physiol 2007;34(9):906-11. https://doi.org/10.1111/j.1440-1681.2007.04638.x PMid:17645639 PMCid:PMC1955221

9. Durak I, Ozturk HS, Elgun S, Cimen MYB, Yalcın S: Erythrocyte nitric oxide metabolism in patients with chronic renal failure. Clin Nephrol 2001;55(6):460-4.

10. Huang LW, Chang KL, Chen CJ, Liu HW. Arginase levels are increased in patients with rheumatoid arthritis. Kaohsiung J Med Sci 2001;17(7):358-63.

11. Brock AA, Chapman SA, Ulman EA, Wu G. Dietery manganese deficency decreases rat hepatic arginase activity. J Nutr 1994;124(3):340-4. https://doi.org/10.1093/ jn/124.3.340

12. Diez AM, Campo ML, Soler G. Trypsin digestion of arginase: Evidence for a stable confirmation manganese directed. Int J Biochem 1992;24(12):1925-32. https://doi.org/10.1016/ 0020-711X(92)90288-C

13. Uslu S, Ozcelik E, Kebapci N, Temel HE, Demirci F, Ergun B, Demirustu C. Effects of serum uric acid levels on the arginase pathway in women with metabolic syndrome. Ir J Med Sci 2016;185(1):259-63. https://doi.org/10.1007/ s11845-015-1347-9 PMid:26232927

14. Kiss A, Tratsiakovich Y, Gonon AT et al. The role of arginase and rho kinase in cardioprotection from remote ischemic perconditioning in non-diabetic and diabetic rat in vivo. PLoS One. 2014;20:9(8):e104731. https://doi.org/10.1371/ journal.pone.0104731 PMid:25140754 PMCid:PMC4139318

15. Seven R, Gelişgen R, Seven A, Erbil Y, Bozbora A, Burçak G. Influence of propylthiouracil treatment on oxidative stress and nitric oxide in Basedow disease patients. J Toxicol Environ Health A. 2001;62(7):495-503. https://doi.org/ 10.1080/152873901300007806 PMid:11289700

16. Hermenegildo C, Medina P, Peiró M, Segarra G, Vila JM, Ortega J, Lluch S. Plasma concentration of asymmetric dimethylarginine, an endogenous inhibitor of nitric oxide synthase, is elevated in hyperthyroid patients. J Clin Endocrinol Metab. 2002;7(12):5636-40. https://doi.org/ 10.1210/jc.2002-020905 PMid:12466365

17. Vargas F, Montes R, Sabio JM, García-Estañ J. Role of nitric oxide in the systemic circulation of conscious hyper- and hypothyroid rats. Gen Pharmacol. 1994;25(5):887-91. https://doi.org/10.1016/0306-3623(94)90091-4

18. Zaman J, Jeddi S, Ghasemi A. The effects of ischemic postconditioning on myocardial function and nitric oxide metabolites following ischemia-reperfusion in hyperthyroid rats. Korean J Physiol Pharmacol. 2014;18(6):481-7. https://doi.org/10.4196/kjpp.2014.18.6. 481 PMid:25598662 PMCid:PMC4296037 
19. Asker ME, Hassan WA, El-Kashlan AM. Experimentally induced hyperthyroidism influences oxidant and antioxidant status and impairs male gonadal functions in adult rats. Andrologia. 2015;47(6):644-54. https://doi.org/10.1111/and.12312 PMid:25220112

20. Moshage H, Kok B, Huizenga JR, Jansen PL. Nitrite and nitrate determinations in plasma: a critical evaluation. Clin Chem 1995;41(6):892-6. https://doi.org/10.1093/clinchem/ 41.6.892 PMid: 7768008

21. Geyer JW, Dabich D. Rapid method for determination of arginase activity in tissue homogenates. Anal Biochem 1971;39(2):412-7. https://doi.org/10.1016/0003-2697(71) 90431-3

22. Brodie KG, Routh MW. Trace analysis of lead in blood, aluminium and manganese in serum and chromium in urine by graphite furnace atomic absorption spectrometry. Clin Biochem 1984;17(1):19-26. https://doi.org/10.1016/ S0009-9120(84)90390-4

23. Yalcın B, Duman C, Cekmen MB et al. The Effects of Propylthyouracil Therapy on the Nitric Oxide, Oxidants, Antioxidants in the Hyperthyroidic Patients. Turk Klinik Biyokimya Derg 2004;2(1):1-7.
24. Vural H, Sirin B, Yilmaz N, Eren I, Delibas N. The role of arginine-nitric oxide pathway in patients with Alzheimer disease. Biol Trace Elem Res 2009;129(1-3):58-64. https://doi.org/10.1007/s12011-008-8291-8 PMid:19099206

25. Aihara K, Nishi Y, Hatano S, Kihara M, Yoshimitsu K, Takeichi $\mathrm{N}$, Ito $\mathrm{T}$, Ezaki $\mathrm{H}$, Usui T. Zinc, copper, manganese, and selenium metabolism in thyroid disease. Am J Clin Nutr 1984;40(1):26-35. https://doi.org/10.1093/ajcn/40.1.26 PMid:6741853

26. Memon NS, Kazi TG, Afridi HI, Baig JA, Sahito OM, Baloch S, Waris M. Correlation of manganese with thyroid function in females having hypo- and hyperthyroid disorders. Biol Trace Elem Res 2015;167:165-71. https://doi.org/10.1007/ s12011-015-0277-8 PMid:25774040

27. Giray B, Arnaud J, Sayek I, Favier A, Hincal F. Trace elements status in multinodular goiter. J Trace Elem Med Biol. 2010;24(2):106-10. https://doi.org/10.1016/j.jtemb.2009. 11.003 PMid:20413068

28. Savchenko OV, Toupeleev PA. Lead, cadmium, manganese, cobalt, zinc and copper levels in whole blood of urban teenagers with non-toxic diffuse goiter. Int J Environ Health Res. 2012;22(1):51-9. https://doi.org/10.1080/09603123. 2011.588324 PMid:21660794 